\section{Positive feedback between Dia1, LARG, and RhoA regulates cell morphology and invasion}

\author{
Thomas M. Kitzing, ${ }^{1,4}$ Arul S. Sahadevan, ${ }^{1,4}$ \\ Dominique T. Brandt, ${ }^{1}$ Helga Knieling, ${ }^{1}$ \\ Sebastian Hannemann, ${ }^{2}$ Oliver T. Fackler, ${ }^{2}$ \\ Jörg Großhans, ${ }^{3}$ and Robert Grosse ${ }^{1,5}$ \\ ${ }^{1}$ Institute of Pharmacology, University of Heidelberg, 69120 \\ Heidelberg, Germany; ${ }^{2}$ Department of Virology, University of \\ Heidelberg, 69120 Heidelberg, Germany; ${ }^{3}$ Zentrum für \\ Molekulare Biologie Heidelberg, University of Heidelberg, \\ 69120 Heidelberg, Germany
}

The RhoA-effector Dia1 controls actin-dependent processes such as cytokinesis, SRF transcriptional activity, and cell motility. Dia1 polymerizes actin through its formin homology (FH) 2 domain. Here we show that Dia1 acts upstream of RhoA independently of its effects on actin assembly. Dia1 binds to the leukemia-associated Rho-GEF (LARG) through RhoA-dependent release of Dia1 autoinhibition. The FH2 domain stimulates the guanine nucleotide exchange activity of LARG in vitro. Our results reveal that Dia1 is necessary for LPA-stimulated Rho/ROCK signaling and bleb-associated cancer cell invasion. Thus, Dia1-dependent RhoA activation constitutes a positive feedback mechanism to modulate cell behavior.

Supplemental material is available at http://www.genesdev.org.

Received January 11, 2007; revised version accepted May 8, 2007.

Diaphanous-related formins (DRFs) are Rho-GTPasebinding proteins that possess conserved functions in actin cytoskeleton dynamics exerted through their formin homology (FH) 2 domains (Goode and Eck 2007). DRFs are involved in essential cellular processes such as cytokinesis, cell movement, and polarity (Faix and Grosse 2006; Gomez et al. 2007), which are frequently deregulated during pathological situations like tumor cell transformation and metastasis (Sahai 2005). The dormant conformation of the DRF Dial is maintained by intramolecular association of its regulatory $\mathrm{N}$ terminus to the diaphanous autoregulatory domain (DAD), which is relieved through binding of active RhoA (Lammers et al. 2005; Otomo et al. 2005a). The catalytic FH2 domain is believed to become "exposed" by conformational changes in the DRFs to promote barbed end actin polymerization by forming a tethered dimer (Xu et al. 2004;

[Keywords: Diaphanous-related formins; RhoA; LARG; actin polymerization; LPA; Rho-kinase]

${ }^{4}$ These authors contributed equally to this work.

${ }^{5}$ Corresponding author.

E-MAIL robert.grosse@pharma.uni-heidelberg.de; FAX 49-06221-548549.

Article is online at http://www.genesdev.org/cgi/doi/10.1101/gad.424807.
Otomo et al. 2005a). The FH2 domain of Dia1 promotes stress fiber formation and transcriptional activation of the MAL/SRF pathway through its actin-polymerizing activity (Copeland and Treisman 2002; Grosse et al. 2003; Miralles et al. 2003). A Dial mutant defective in FH2 dimerization interferes with lysophosphatidic acid (LPA)-induced stress fiber formation and SRF activity (Copeland and Treisman 2002), suggesting that Dial is part of LPA signal transduction known to play an important role in cell proliferation and metastasis of a variety of human cancers (Mills and Moolenaar 2003). LPA receptors belong to the group of G-protein-coupled receptors that activate the heterotrimeric $\mathrm{G}$-proteins $\mathrm{G}_{12}$ and $\mathrm{G}_{13}$, which can bind to RGS-containing Rho-GEFs such as leukemia-associated Rho-GEF (LARG), initially isolated from a patient with acute myeloid leukemia (AML) (Kourlas et al. 2000; Vazquez-Prado et al. 2004). Rhodependent mechanisms have emerged as critical processes in tumor progression (Sahai and Marshall 2002; Lozano et al. 2003), and evidence exists that Rho/ROCK function is essential to promote a specific type of rounded bleb-associated mode of cell invasion (Sahai and Marshall 2003; Wyckoff et al. 2006). However, the role of DRFs in tumor cell behavior has not been investigated.

In this study, we provide evidence for an essential role of the Rho-effector Dial in LPA-mediated Rho/ROCK activity for tumor cell morphology and invasion that involves LARG, thereby constituting a positive feedback loop toward RhoA.

\section{Results and Discussion}

To explore the role of Dial in the regulation of RhoA, we performed GTPase activity assays (Goulimari et al. 2005). HEK293 cells were used to achieve transfection efficiencies $>70 \%$ to determine whether versions of Dial lacking the regulatory $\mathrm{N}$ terminus $(\Delta \mathrm{DiaN})$ (Fig. 1A) required for autoinhibition could induce endogenous RhoA activity. Interestingly, $\Delta$ DiaN caused substantial activation of RhoA (Fig. 1B). Active DAD-deletion mutants $(\triangle \mathrm{DAD})$ of mouse Dia1, Dia2, and Dia3 also stimulated RhoA but not Cdc42 activity, indicating that this is a shared characteristic among DRFs of this family (Fig. 1C). Dial also activated Rac as previously suggested (Tsuji et al. 2002; data not shown). Further analysis revealed that the FH2 domain was sufficient to activate RhoA (Fig. 1D). Since the FH2 is also sufficient for actin assembly and activation of SRF, we tested their possible involvement, indicative of an indirect mechanism. For this we treated cells with Latrunculin B, which sequesters actin monomers and prevents SRF activation (Sotiropoulos et al. 1999). Although Latrunculin B effectively blocked FH2-induced SRF activation as expected (Fig. $1 \mathrm{E})$, it failed to inhibit RhoA activation by $\mathrm{FH} 2$ and LARG, while transfection of C3 transferase as a control blocked RhoA activity (Fig. 1D). Interestingly and in agreement with previous findings (Copeland and Treisman 2002), we observed that FH2-induced SRF activity was significantly inhibited by C3 (Fig. 1E), suggesting that upstream RhoA contributes to FH2-exerted actin dynamics. The FH2 domain dimerizes involving its N-terminal lasso loop linker in order to nucleate actin filaments, whereas the core FH2 (FH2core) lacking the lasso behaves as a barbed end capper (Shimada et al. 2004; 


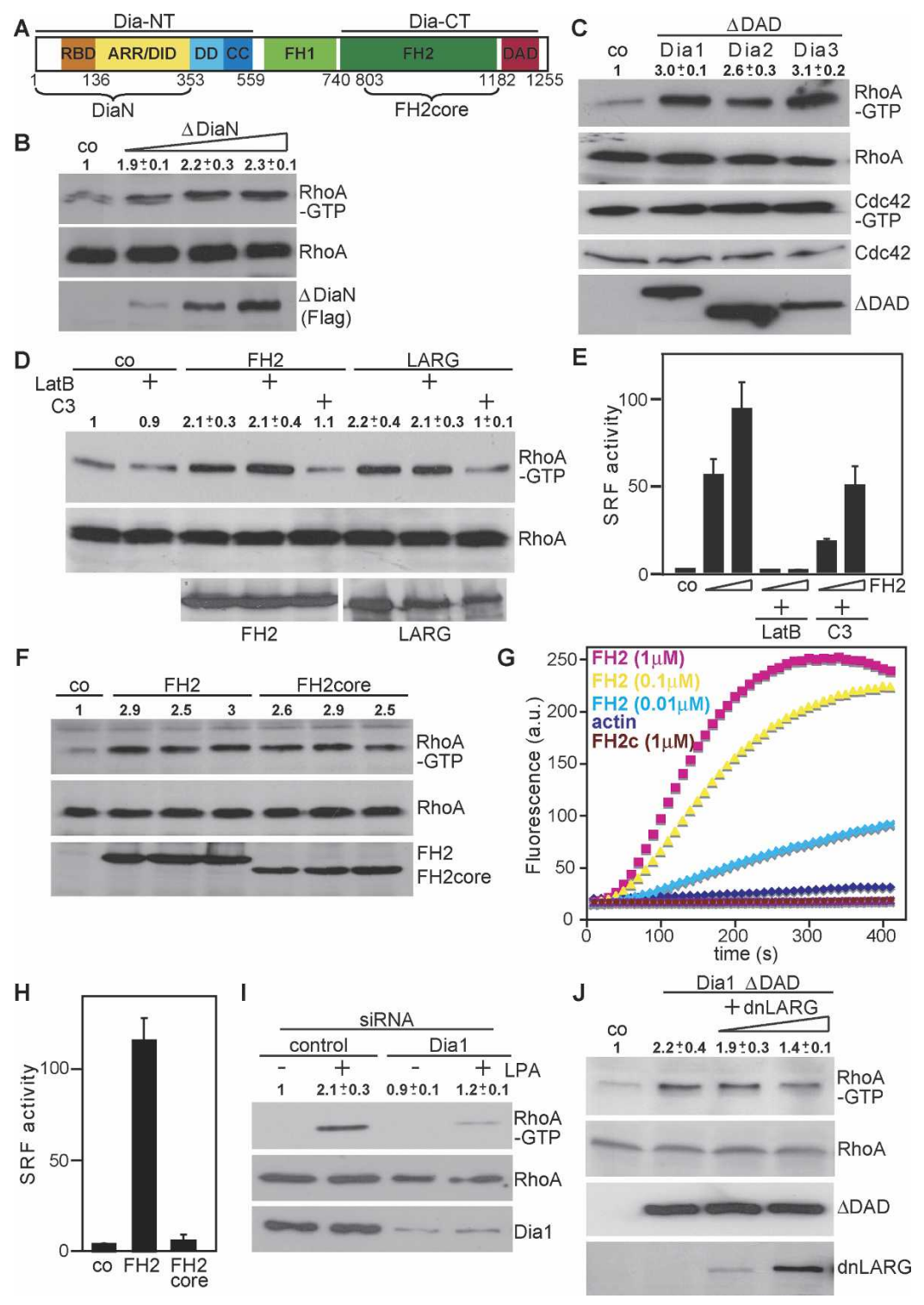

Figure 1. Role of Dial in activation of RhoA. $(A)$ Schematic representation of mDial. $(B)$ Cells were transfected with control plasmid or increasing amounts of plasmids $(0.2,0.5,1.0 \mu \mathrm{g})$ encoding $\triangle \mathrm{DiaN}$ and subjected to RhoA-GTP pull-down assays. RhoA and Flag- $\Delta$ DiaN were analyzed by Western blotting. (C) Activation of RhoA but not Cde 42 by $\triangle \mathrm{DAD}$ expression plasmids for Dial-3 is shown. Active RhoA and Cdc42 were precipitated simultaneously from cell extracts. (D) FH2-induced RhoA activity in the absence or presence of $0.5 \mu \mathrm{M}$ Latrunculin B (LatB) or in the absence or presence of C3 plasmid $(0.5 \mu \mathrm{g})$. (E) Cells expressing FH2 (0.1 and $0.3 \mu \mathrm{g})$ together with the SRF reporter were cotransfected with $\mathrm{C} 3(0.1 \mu \mathrm{g})$ or pretreated with LatB as indicated. Reporter activity is shown as the mean \pm SEM of three independent experiments. $(F)$ FH2 or FH2core was transfected. The amount of Rho-GTP bound, of total RhoA, and of expressed $\mathrm{FH} 2$ and FH2core proteins was analyzed by Western blotting. $(G)$ Shown is FH2-induced actin polymerizing versus $\mathrm{FH} 2$ core capping activity using pyreneactin assembly assays with indicated components. $(H)$ Expression plasmids for FH2 or FH2core were transfected with an SRF reporter. Data represent the mean \pm SEM of three independent experiments. $(I)$ Dial is required for RhoA activation by LPA as shown by siRNA. Cells were untreated or stimulated with LPA $(10 \mu \mathrm{M}, 5 \mathrm{~min})$ as indicated, and activated RhoA was precipitated. Cell extracts were immunoblotted for the indicated proteins. (J) HEK293 cells were transfected with FlagDia1 $\triangle \mathrm{DAD}$ and increasing amounts of expression plasmids encoding dnLARG $(1.0,5.0 \mu \mathrm{g})$. Activated RhoA and cell extracts were immunoblotted for the indicated proteins. All Western blot quantifications shown are the mean \pm SEM of at least two independent experiments..
Otomo et al. 2005b). Therefore, we compared FH2core and $\mathrm{FH} 2$ for RhoA activity and actin polymerization. We found that both domains activate RhoA (Fig. 1F), but only the FH2 was able to stimulate SRF and actin polymerization, whereas the FH2core inhibited SRF and basal actin polymerization due to its capping activity (Fig. 1G,H). These data demonstrate that Dial stimulates RhoA activity independently of its actin nucleation activity, thus representing a novel function of this conserved protein.

Next we tested the possibility that Dial may be part of a signal transduction pathway toward RhoA. For this we stimulated cells with LPA under conditions in which Dial expression was suppressed by RNA interference. We observed that Dial is required for full RhoA activation by LPA (Fig. 1I), indicating that Dial is an essential component of LPA signal transduction toward RhoA. Since this function is separable from the actin nucleation activity, it is an independent and additional function of Dial. Activation of RhoA requires GEF activity. We speculated about an involvement of LARG, based on the facts that (1) LARG, like Dia1, is implicated in LPA signaling by interaction with $\mathrm{G} \alpha_{12 / 13}$ as well as by using a dominant-negative mutant of LARG (dnLARG) (Vogt et al. 2003; Tanabe et al. 2004; Vazquez-Prado et al. 2004); and (2) the Drosophila LARG homolog dRhoGEF2 colocalizes with Diaphanous at the furrow canal during cellularization (Grosshans et al. 2005). To investigate whether LARG is involved in Dial-induced stimulation of RhoA, we used the previously characterized dnLARG lacking the DH/PH domains (Fig. 2A; Vogt et al. 2003). Despite relatively low expression levels, dnLARG partially but significantly inhibited Dial- $\triangle \mathrm{DAD}$-induced RhoA activity (Fig. 1J), indicating that LARG is involved in RhoA-GTP formation through Dial.

How can Dial regulate RhoA activity? Since dnLARG interfered with Dial-induced RhoA activity and both proteins function in LPA signaling toward RhoA, we tested whether LARG and Dial associate. Using Dial antibodies, we were able to coimmunoprecipitate Dial together with endogenous or transfected LARG (Fig. 2B; Supplementary Fig. 1). We also tested if dishevelled is 


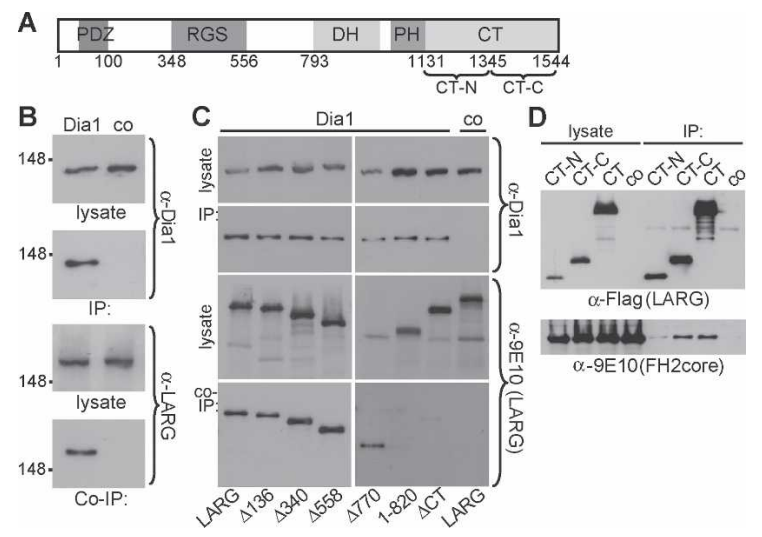

Figure 2. Dial interacts with LARG. (A) Schematic representation of LARG. (RGS) Regulator of G protein signaling; (DH) Dbl homology; $(\mathrm{PH})$ pleckstrin homology. $(B)$ Cells maintained in $10 \%$ serum were lysed before immunoprecipitation with $\alpha$-Dial or control antiserum (co). Cell lysates and precipitates (IP) were analyzed by immunoblot as indicated. $(C)$ Lysates were prepared from cells expressing myc-LARG derivatives or full-length LARG. Immunoprecipitates (IP) prepared using $\alpha$-Dial were analyzed for associating LARG derivatives (Co-IP) by immunoblotting as indicated. $(D)$ Lysates from cells expressing FH2core and LARG C-terminal mutants were immunoprecipitated and analyzed by immunoblotting as indicated.

present, as it was shown to bind the DRF Daam1 for Wnt/Frizzled activation of RhoA during Xenopus gastrulation (Habas et al. 2001), but we did not detect dishevelled in the Dia1/LARG complex (data not shown).

LARG belongs to the RGS domain-containing RhoGEFs, consisting of two additional members, p115RhoGEF and PDZ-RhoGEF (PRG) (Vazquez-Prado et al. 2004). Hence, we assessed the specificity of the Dial/ LARG association. We found that Dial interaction with LARG is specific among this RhoGEF family since PRG or p115RhoGEF did not coimmunoprecipitate with Dial (Supplementary Fig. 1). However, we cannot exclude the possibility that Dial influences additional RhoGEFs or RhoGTPase-regulating proteins.

To determine the regions required for association with Dial, a series of LARG truncation mutants was tested. Only LARG mutants containing the $\mathrm{C}$ terminus coimmunoprecipitated with Dial (Fig. 2C). Since the FH2core domain of Dial is sufficient to induce RhoA activity, we tested whether the LARG C terminus and the FH2core domain would associate. Indeed, we could coimmunoprecipitate the $\mathrm{FH} 2$ core domain with the $\mathrm{C}$ terminus of LARG (Fig. 2D). To further define the region within the LARG C terminus, we coexpressed its $\mathrm{N}$ - or $\mathrm{C}$-terminal regions (CT-N and CT-C, respectively) with FH2core. As shown in Figure 2D, only the C-terminal half of the LARG C terminus efficiently coimmunoprecipitated the FH2core domain, indicating that these regions are responsible for the association. These data were confirmed using protein overlay assays (Supplementary Fig. 2).

The association of $\mathrm{FH} 2$ core with the $\mathrm{C}$ terminus of LARG suggested that activated Dial regulates the LARG $\mathrm{C}$ terminus. The release of Dial autoinhibition through binding of active RhoA to Dial-NT (Fig. 1A) can be reconstituted in vitro by measuring FH2-DAD (CT) domain-induced actin polymerization (Fig. $3 \mathrm{~A}$; $\mathrm{Li}$ and Higgs 2005; Brandt et al. 2007). To address whether autoinhibition of Dial regulates its interaction with LARG, we performed GST pull-down assays with LARG
CT-C and the Dial-NT and Dial-CT fragments in the absence or presence of active RhoAV14. Interestingly, association between Dial-CT and LARG-CT-C was strongly inhibited by the addition of Dial-NT (Fig. 3B). Moreover, this inhibition was overcome by the addition of active RhoA to the complex (Fig. 3C). These data demonstrate that the interaction between Dial and LARG is controlled by RhoA-induced release of Dial autoinhibition. This suggests the existence of a positive feedback loop involving RhoA, Dial, and LARG. Interestingly, conformational changes of the $\mathrm{C}$ terminus of LARG (CT) appear to be mediated by the interaction of $\mathrm{N}$ - and C-terminal regions, while the FH2core domain can interfere with CT-N/CT-C binding in a dose-dependent manner (Supplementary Fig. 2), indicating that Dial may modulate LARG C-terminal conformation, known to control LARG activity in vivo (Chikumi et al. 2004).

To directly assess if Dial affects LARG activity, we performed in vitro GEF assays using a recombinant LARG consisting of the $\mathrm{DH} / \mathrm{PH}$ domain and the $\mathrm{C}$ terminus. LARG efficiently accelerated the release of GDP from RhoA in a dose-dependent manner (Fig. 3D). Under these conditions, the lowest measurable concentration of LARG was used as a baseline activity to which recombinant FH2 was added. This resulted in a concentrationdependent acceleration of LARG activity (Fig. 3E). These
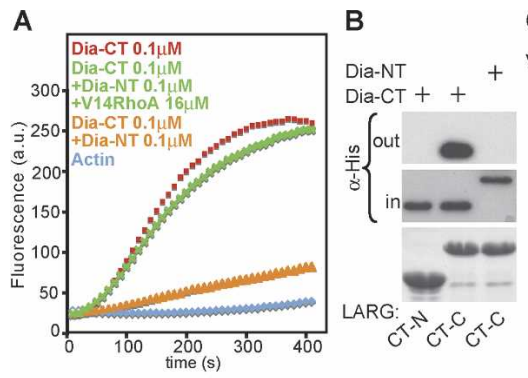

C
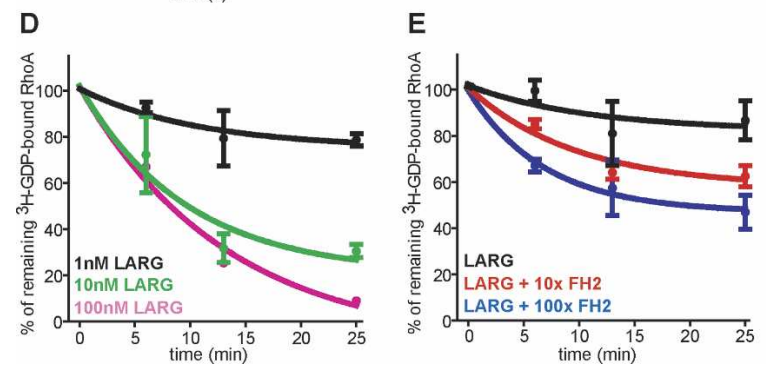

Figure 3. Dial stimulates LARG GEF activity. (A) Actin assembly assays of Dial-CT show release of NT-induced inhibition by RhoAV14. (B) His-Dia-NT and His-Dia-CT proteins were incubated with GST-LARG C-terminal regions, and complexes were analyzed by immunoblot using $\alpha$-His antibody. Coomassie staining for GSTLARG CT-N and CT-C is shown in the bottom panel. $(C)$ GST pull-downs show association of LARG CT-C with Dia1-CT and the release of NT-induced binding inhibition by RhoAV14. Complexes were analyzed by immunoblot as indicated. Coomassie staining for GST-LARG CT-N and CT-C is shown in the bottom panel. One representative out of four independent experiments is shown. $(D)$ Indicated concentrations of GST-LARG incubated with $\left[8-{ }^{3} \mathrm{H}\right]$ GDPloaded RhoA. $\left[8-{ }^{3} \mathrm{H}\right]$ GDP-bound RhoA $(\%)$ is plotted against incubation time. Shown is the mean \pm SEM of three independent experiments. (E) One nanomolar GST-LARG was incubated with $\left[8-{ }^{3} \mathrm{H}\right]$ GDP-loaded RhoA with 100 -fold molar excess of GST or with 10- and 100-fold molar excess of GST-FH2. [8- $\left.{ }^{-3} \mathrm{H}\right]$ GDP-bound RhoA $(\%)$ is plotted against incubation time. Shown is the mean \pm SEM of three independent experiments. 
results show that Dial can stimulate the GEF activity of LARG. We propose that the Dial/LARG interaction results in conformational changes of regulatory regions within the LARG $\mathrm{C}$ terminus.

LARG was identified as a gene fusion rearranged in AML (Kourlas et al. 2000). Up-regulated activities of RhoA have been reported for a variety of human cancers (Sahai and Marshall 2002; Lozano et al. 2003). Here we show that Dial promotes RhoA activity via interaction with LARG and that Dial is required for LPA-mediated RhoA activity. Since LPA is known to play an important role in tumor development and progression promoting cancer cell metastasis and invasion (Mills and Moolenaar 2003), we tested the role of Dial in tumor cell invasion. One mode of tumor cell invasion in three-dimensional (3D) matrices is represented by the rounded mode of motility, for which Rho/ROCK signaling is necessary and sufficient (Sahai and Marshall 2003; Wyckoff et al. 2006). After optimizing the conditions for small interfering RNA (siRNA_ toward Dial (Fig. 4A,B), we used highly invasive MDA-MB-435 human cancer cells (Sellappan et al. 2004; Rae et al. 2006), which express Dia1, Dia2 (Fig. 4B), and Dia3 (data not shown), and tested their ability to migrate into LPA-containing 3D matrices when Dia1 or Dia2 expression was down-regulated. Interestingly, knockdown of Dial efficiently and significantly inhibited the total number of tumor cells that have invaded as well as the overall invasion distance (Fig. 4D,E; Supplementary Videos 1, 2), whereas random MDA-MB-435 cell migration under two-dimensional (2D) tissue culture conditions was slightly increased (Fig. 4C). Knockdown of Dia2 did not inhibit cell invasion (data not shown). Similar results were obtained in A375m 2 melanoma cells (data not shown), which also use the rounded mode of motility (Sahai and Marshall 2003). We next determined the involvement of LARG in MDA-MB-435 cell invasion. For this, we transfected GFP-dnLARG, GFP alone, or cotransfected with LARG1-820 as a control (transfection efficiencies were $\sim 1 \%$ ) and assessed the GFP-positive cells invaded into the Matrigel. This revealed that dnLARG inhibited cell invasion (Fig. 4F) but not random 2D migration (Fig. 4C). Inhibition of ROCK with $10 \mu \mathrm{M}$ Y27632 blocked invasion of MDA-MB-435 cells as expected, while treatment with the Src-kinase inhibitor PP1 had no effect (Fig. 4G). Consistently, usage of siRNAs against LARG significantly reduced cell invasion (Fig. 4H,I). Together, these data suggest that LARG is involved in cancer cell invasion.

In order to understand better the mechanisms underlying the dependence on Dial for tumor cell invasion, we analyzed the MDA-MB-435 cell morphologies in Matrigel. We observed that these cells use the rounded blebassociated mode of motility (Supplementary Video 3), while in $2 \mathrm{D}$ culture these cells displayed a mesenchymal-like cell morphology (data not shown). Analysis of F-actin using phalloidin staining revealed that untreated or control siRNA-treated MDA-MB-435 cells showed extensive formation of membrane blebs when contacting and invading Matrigel (Fig. 5B; Supplementary Video 4). However, cells that were silenced for Dial (Fig. 5A) displayed strikingly different morphologies and lost their ability to promote membrane blebbing (Fig. 5B; Supplementary Video 5).

Bleb-associated cell invasion requires ROCK (Sahai and Marshall 2003) to control contractile force through
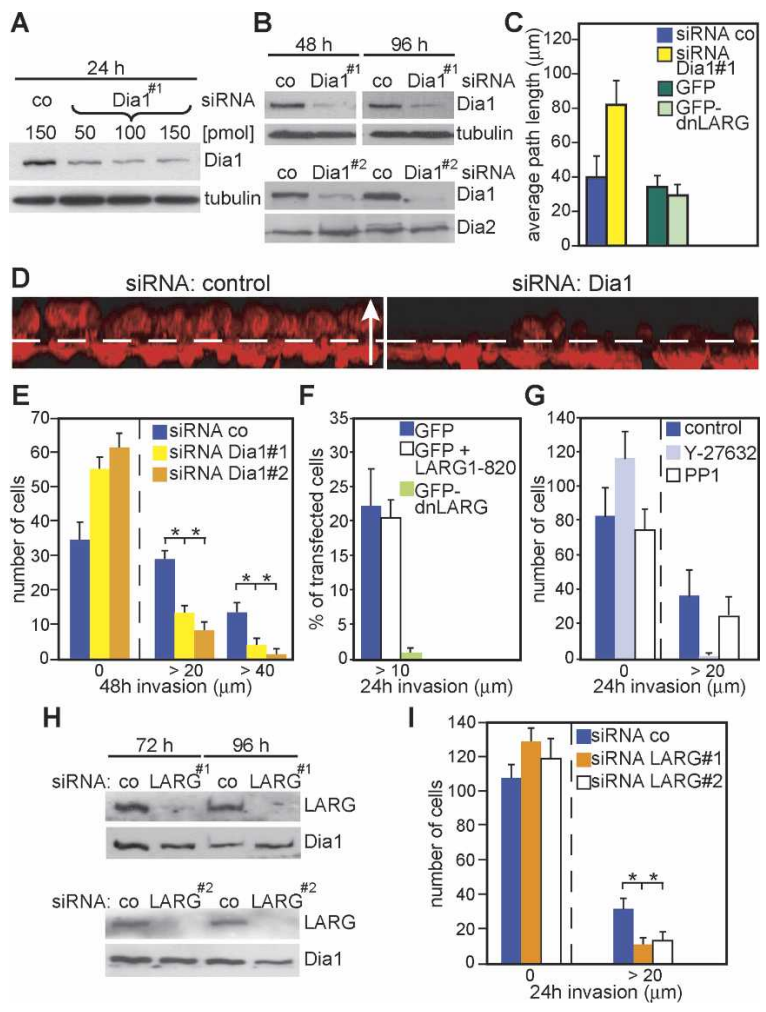

Figure 4. Dial is required for MDA-MB-435 cancer cell invasion. (A) Cells treated with different amounts of siRNA as indicated and analyzed by immunoblotting. $(B)$ Cells treated with control siRNA or siRNA against Dial were immunoblotted for the indicated proteins. (C) Cells transfected with indicated siRNAs or plasmids were analyzed for random motility. Data are expressed as mean \pm SD of three independent experiments. (D) Representative 3D reconstructions of invaded cells transfected with siRNA as indicated. Cells were stained for F-actin (red); dashed line indicates the approximate position of the Transwell membrane; the arrow $(50 \mu \mathrm{m})$ indicates the direction of movement. $(E)$ Cells were allowed to invade for 48 $\mathrm{h}$ into Matrigel before counting at indicated invasion distances. The average of cell number from three independent experiments \pm SD is shown. (F) MDA-MB-435 cells transfected with indicated plasmids were analyzed in invasion assays. The percentage of GFP-positive cells invaded is shown from two independent experiments counting $>300$ cells. $(G)$ The number of cells invaded into Matrigel containing LPA and indicated inhibitors is shown. $(H, I)$ Cells treated with indicated siRNAs were analyzed for invasion.

myosin activity (Riento and Ridley 2003). When basal as well as LPA-stimulated phosphorylation of myosin light chain (MLC), a ROCK substrate (Riento and Ridley 2003), was determined in MDA-MB-435 cells in the presence or absence of siRNA against LARG or Dial, we found that MLC phosphorylation was strongly reduced (Fig. 5C-E) in contrast to Dia2 siRNA (Fig. 5F). To investigate whether Dial promotes ROCK activity through RhoA, we used HEK293 cells to efficiently express the FH2 domain with ROCK-I before determining in vitro kinase activities using either MBP or MLC as substrates. Interestingly, we found that active Dial increased ROCK activity in a Rho-dependent manner (Fig. 5G). These results clearly show that activation of RhoA by Dial leads to an increase in ROCK activity to promote the MLC phosphorylation required for bleb-associated cell invasion.

Dial is a well-established downstream effector of ac- 
Kitzing et al.
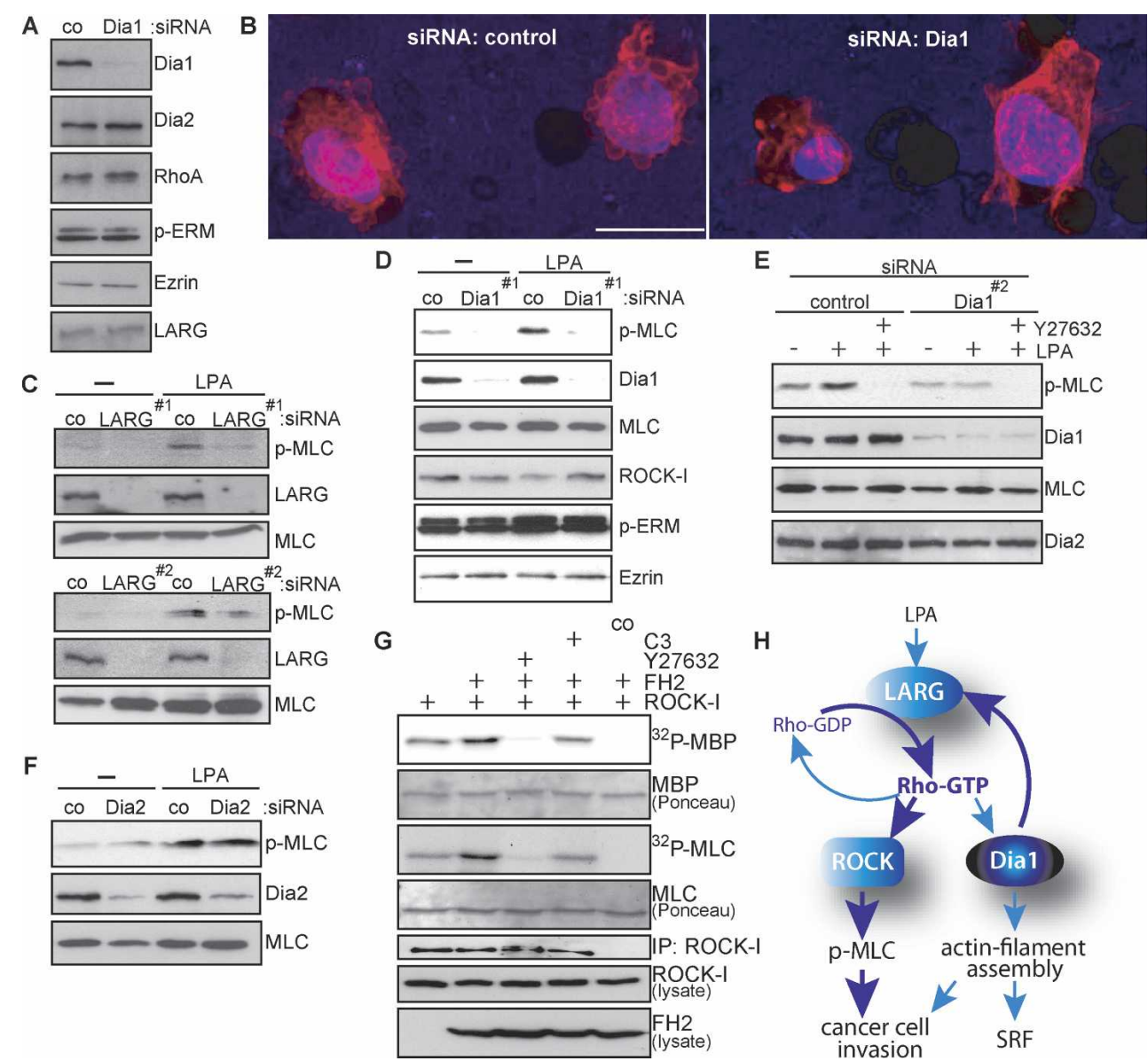

E

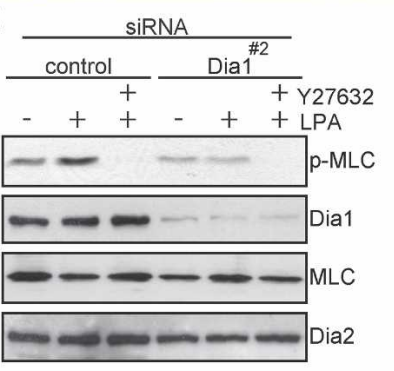

$\mathrm{F}$
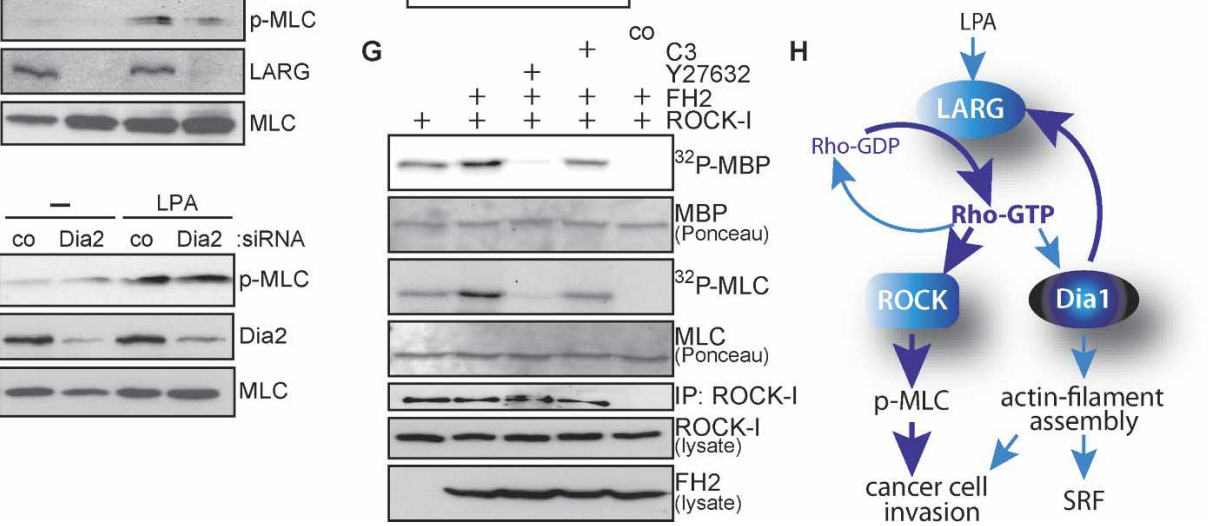

Figure 5. Dial is required for ROCK signaling and cancer cell morphology. (A) MDA-MB-435 cells were treated with control siRNA or siRNA against Dia1, and cell extracts were immunoblotted for the indicated proteins. (B) Representative 3D reconstructions of MDA-MB-435 cells treated in $A$ invading through the porous membrane into the Matrigel. Cells were stained using DAPI (blue) to visualize nuclei and rhodaminephalloidin (red) to visualize F-actin. Bar, $20 \mu \mathrm{m}$. (C-F) MDA-MB-435 cells treated with indicated siRNAs were stimulated with $10 \mu \mathrm{M}$ LPA for 10 min. Cell extracts were immunoblotted for the indicated proteins. $(G)$ myc-ROCK-I was immunoprecipitated from HEK293 cells cotransfected with Flag-FH2 or C3 or treated with $10 \mu \mathrm{M}$ Y27632 as indicated, and subjected to kinase assays using MBP or MLC as substrates. Kinase reactions were separated by SDS-PAGE, and phosphorylated substrates were visualized by autoradiography $\left({ }^{32} \mathrm{P}-\mathrm{MBP},{ }^{32} \mathrm{P}-\mathrm{MLC}\right)$. Immobilized rabbit IgG was used as a control (co). One representative out of three independent experiments with similar results is shown. (H) Proposed hypothetical model for Dial-mediated feedback activation of RhoA through LARG.

tive RhoA. Our results presented here reveal an unexpected and essential role for Dial in the activation of the Rho/ROCK signal transduction pathway and subsequent bleb-associated cancer cell motility. We provide evidence that Dial is required and sufficient for full LPAinduced activation of RhoA and downstream ROCK signaling. This effect can be mediated through interaction of Dial with LARG. The data shown here imply a novel signaling module by which Dial, in addition to its role as a downstream RhoA effector, can function upstream of RhoA. This constitutes a positive feedback mechanism (Fig. 5H) amplifying signal-regulated cellular effects such as tumor cell invasion by activating RhoA and its effector ROCK.

\section{Materials and methods}

Plasmids, siRNA, transfections, and cell-based assays

Plasmids were generated using standard procedures. All siRNA oligos were from IBA. GTPase pull-down assays, immunoprecipitations, and Rho-kinase and SRF activity assays were performed in HEK293 or NIH3T3 cells. See the Supplemental Material for details.
Protein purification, actin assembly, and guanyl-nucleotide exchange assays

Proteins were produced and purified in Escherichia coli strain DE3 as GST or His fusions. Actin polymerization was monitored as described (Brandt et al. 2007). Guanyl-nucleotide exchange assays were performed using GST-RhoA loaded with $\left[8-{ }^{3} \mathrm{H}\right]$ GDP. See the Supplemental Material for full details.

$3 D$ matrigel invasion and confocal analysis

Human MDA-MB-435 cancer cells were used for invasion assays. Assays were analyzed using confocal microscopy (Leica TCS SP2). See the Supplemental Material for full details.

\section{Acknowledgments}

We thank R. Treisman and B. Di Ventura for critical reading of the manuscript. We are indebted to G. Stier for plasmids, reagents, and expertise in protein purification. We thank S. Offermanns for support. We thank S. Narumiya and S. Gutkind for plasmids and A. Rippberger and J. Stastná for technical assistance. O.T.F. is supported by the CHS Stiftung. This work was funded by the Emmy Noether Program of the DFG (GR2111/ 1-2) to R.G. 


\section{References}

Brandt, D.T., Marion, S., Griffiths, G., Watanabe, T., Kaibuchi, K., and Grosse, R. 2007. Dial and IQGAP1 interact in cell migration and phagocytic cup formation. J. Cell Biol. (in press).

Chikumi, H., Barac, A., Behbahani, B., Gao, Y., Teramoto, H., Zheng, Y., and Gutkind, J.S. 2004. Homo- and hetero-oligomerization of PDZ RhoGEF, LARG and p115RhoGEF by their C-terminal region regulates their in vivo Rho GEF activity and transforming potential. Oncogene 23: 233-240.

Copeland, J.W. and Treisman, R. 2002. The diaphanous-related formin mDial controls serum response factor activity through its effects on actin polymerization. Mol. Biol. Cell 13: 4088-4099.

Faix, J. and Grosse, R. 2006. Staying in shape with formins. Dev. Cell 10: 693-706.

Gomez, T.S., Kumar, K., Medeiros, R.B., Shimizu, Y., Leibson, P.J., and Billadeau, D.D. 2007. Formins regulate the actin-related protein 2/3 complex-independent polarization of the centrosome to the immunological synapse. Immunity 26: 177-190.

Goode, B.L. and Eck, M.J. 2007. Mechanism and function of formins in control of actin assembly. Annu. Rev. Biochem. 76: 32.1-32.35.

Goulimari, P., Kitzing, T.M., Knieling, H., Brandt, D.T., Offermanns, S., and Grosse, R. 2005. G $\alpha 12 / 13$ is essential for directed cell migration and localized Rho-Dial function. J. Biol. Chem. 280: 42242-42251.

Grosse, R., Copeland, J.W., Newsome, T.P., Way, M., and Treisman, R. 2003. A role for VASP in RhoA-diaphanous signalling to actin dynamics and SRF activity. EMBO J. 22: 3050-3061.

Grosshans, J., Wenzl, C., Herz, H.M., Bartoszewski, S., Schnorrer, F., Vogt, N., Schwarz, H., and Muller, H.A. 2005. RhoGEF2 and the formin Dia control the formation of the furrow canal by directed actin assembly during Drosophila cellularisation. Development 132: 1009-1020.

Habas, R., Kato, Y., and He, X. 2001. Wnt/Frizzled activation of Rho regulates vertebrate gastrulation and requires a novel Formin homology protein Daam1. Cell 107: 843-854.

Kourlas, P.J., Strout, M.P., Becknell, B., Veronese, M.L., Croce, C.M., Theil, K.S., Krahe, R., Ruutu, T., Knuutila, S., Bloomfield, C.D., et al. 2000. Identification of a gene at $11 \mathrm{q} 23$ encoding a guanine nucleotide exchange factor: Evidence for its fusion with MLL in acute myeloid leukemia. Proc. Nat1. Acad. Sci. 97: 2145-2150.

Lammers, M., Rose, R., Scrima, A., and Wittinghofer, A. 2005. The regulation of mDial by autoinhibition and its release by $\mathrm{Rho}^{\star} \mathrm{GTP}$. EMBO J. 24: 4176-4187.

Li, F. and Higgs, H.N. 2005. Dissecting requirements for auto-inhibition of actin nucleation by the formin, mDial. J. Biol. Chem. 280: 69866992.

Lozano, E., Betson, M., and Braga, V.M. 2003. Tumor progression: Small GTPases and loss of cell-cell adhesion. Bioessays 25: 452-463.

Mills, G.B. and Moolenaar, W.H. 2003. The emerging role of lysophosphatidic acid in cancer. Nat. Rev. Cancer 3: 582-591.

Miralles, F., Posern, G., Zaromytidou, A.I., and Treisman, R. 2003. Actin dynamics control SRF activity by regulation of its coactivator MAL. Cell 113: 329-342.

Otomo, T., Otomo, C., Tomchick, D.R., Machius, M., and Rosen, M.K. 2005a. Structural basis of Rho GTPase-mediated activation of the formin mDial. Mol. Cell 18: 273-281.

Otomo, T., Tomchick, D.R., Otomo, C., Panchal, S.C., Machius, M., and Rosen, M.K. 2005b. Structural basis of actin filament nucleation and processive capping by a formin homology 2 domain. Nature 433: 488-494.

Rae, J.M., Creighton, C.J., Meck, J.M., Haddad, B.R., and Johnson, M.D. 2006. MDA-MB-435 cells are derived from M14 melanoma cells-A loss for breast cancer, but a boon for melanoma research. Breast Cancer Res. Treat. doi: 10.1007/s10549-006-9392-8.

Riento, K. and Ridley, A.J. 2003. Rocks: Multifunctional kinases in cell behaviour. Nat. Rev. Mol. Cell Biol. 4: 446-456.

Sahai, E. 2005. Mechanisms of cancer cell invasion. Curr. Opin. Genet. Dev. 15: 87-96.

Sahai, E. and Marshall, C.J. 2002. RHO-GTPases and cancer. Nat. Rev. Cancer 2: 133-142.

Sahai, E. and Marshall, C.J. 2003. Differing modes of tumour cell invasion have distinct requirements for Rho/ROCK signalling and extracellular proteolysis. Nat. Cell Biol. 5: 711-719.
Sellappan, S., Grijalva, R., Zhou, X., Yang, W., Eli, M.B., Mills, G.B., and Yu, D. 2004. Lineage infidelity of MDA-MB-435 cells: Expression of melanocyte proteins in a breast cancer cell line. Cancer Res. 64: 3479-3485.

Shimada, A., Nyitrai, M., Vetter, I.R., Kuhlmann, D., Bugyi, B., Narumiya, S., Geeves, M.A., and Wittinghofer, A. 2004. The core FH2 domain of diaphanous-related formins is an elongated actin binding protein that inhibits polymerization. Mol. Cell 13: 511-522.

Sotiropoulos, A., Gineitis, D., Copeland, J., and Treisman, R. 1999. Sig nal-regulated activation of serum response factor is mediated by changes in actin dynamics. Cell 98: 159-169.

Tanabe, S., Kreutz, B., Suzuki, N., and Kozasa, T. 2004. Regulation of RGS-RhoGEFs by G $\alpha 12$ and G $\alpha 13$ proteins. Methods Enzymol. 390 285-294.

Tsuji, T., Ishizaki, T., Okamoto, M., Higashida, C., Kimura, K., Furuyashiki, T., Arakawa, Y., Birge, R.B., Nakamoto, T., Hirai, H., et al. 2002. ROCK and mDial antagonize in Rho-dependent Rac activation in Swiss 3T3 fibroblasts. J. Cell Biol. 157: 819-830.

Vazquez-Prado, J., Basile, J., and Gutkind, J.S. 2004. Modular architecture and novel protein-protein interactions regulating the RGS-containing Rho guanine nucleotide exchange factors. Methods Enzymol. 390: 259-285.

Vogt, S., Grosse, R., Schultz, G., and Offermanns, S. 2003. Receptordependent RhoA activation in G12/G13-deficient cells: Genetic evidence for an involvement of Gq/G11. J. Biol. Chem. 278: 2874328749.

Wyckoff, J.B., Pinner, S.E., Gschmeissner, S., Condeelis, J.S., and Sahai, E. 2006. ROCK- and myosin-dependent matrix deformation enables protease-independent tumor-cell invasion in vivo. Curr. Biol. 16: 15151523.

Xu, Y., Moseley, J.B., Sagot, I., Poy, F., Pellman, D., Goode, B.L., and Eck, M.J. 2004. Crystal structures of a Formin Homology-2 domain reveal a tethered dimer architecture. Cell 116: 711-723. 


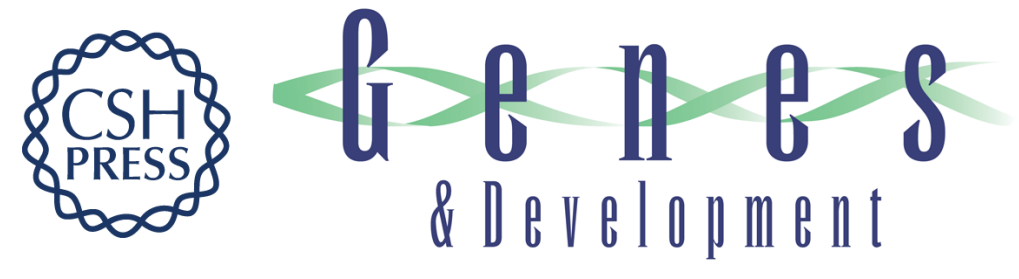

\section{Positive feedback between Dia1, LARG, and RhoA regulates cell morphology and invasion}

Thomas M. Kitzing, Arul S. Sahadevan, Dominique T. Brandt, et al.

Genes Dev. 2007, 21:

Access the most recent version at doi:10.1101/gad.424807

Supplemental
Material http://genesdev.cshlp.org/content/suppl/2007/06/12/21.12.1478.DC1

References This article cites 30 articles, 10 of which can be accessed free at: http://genesdev.cshlp.org/content/21/12/1478.full.html\#ref-list-1

License

Email Alerting

Receive free email alerts when new articles cite this article - sign up in the box at the top Service right corner of the article or click here.

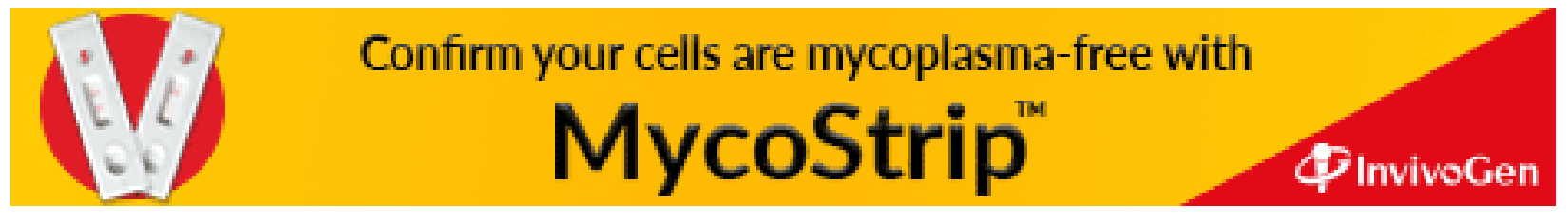

